\title{
TEORIA QUEER, NÚMEROS BINÁRIOS E EDUCAÇÃO MATEMÁTICA: ESTRANHANDO A MATEMÁTICA EM PROL DE UMA HÉXIS POLÍTICA
}

\author{
Queer Theory, binary numbers and mathematics education: queering mathematics in \\ benefit of a political héxis
}

Maurício Rosa

\begin{abstract}
Resumo
Este artigo objetiva debater como a educação matemática pode ajudar a sustentar a luta da população LGBTQIA $+{ }^{1}$ em termos de resistência e sobrevivência enquanto forma de se educar pela matemática para a compreensão/constituição da héxis política, frente ao respeito, à manifestação e à emersão das subjetividades de gênero. Assim, neste artigo teórico, explanamos o conceito de héxis política em conexão com a Teoria Queer, discutimos o sistema sexo-gênero sob um viés crítico e propomos uma reflexão didáticopedagógica sobre números binários (possível de ser efetivada em uma aula de matemática), a fim de suscitar a compreensão da ampliação das tipologias de gênero no mundo, em consonância com o respeito às diferenças. Concluímos que, se propusermos, cada vez mais, atividadesmatemáticas que sejam libertadoras e que considerem a própria matemática como campo de estudo que se dedica a educar para a cidadania e democracia, provavelmente teremos uma sociedade mais humanitária.
\end{abstract}

Palavras-chave: Gênero; ASCII; Tecnologias Digitais; Pensamento Computacional; Diversidade.

\begin{abstract}
This article aims to debate how mathematics education can help to support the struggle of the
\end{abstract}

\footnotetext{
1 [...] L = Lésbicas - São mulheres que sentem atração afetiva/sexual pelo mesmo gênero, ou seja, outras mulheres. G = Gays - São homens que sentem atração afetiva/sexual pelo mesmo gênero, ou seja, outros homens. $\mathrm{B}=$ Bissexuais - Diz respeito aos homens e mulheres que sentem atração afetivo/sexual pelos gêneros masculino e feminino. $\mathrm{T}=$ Transexuais - A transexualidade não se relaciona com a orientação sexual, mas se refere à identidade de gênero. Dessa forma, corresponde às pessoas que não se identificam com o gênero atribuído em seu nascimento. As travestis também são incluídas neste grupo. Porém, apesar de se identificarem com a identidade feminina constituem um terceiro gênero. $Q=$ Queer -Pessoas com o gênero 'Queer' são aquelas que transitam entre as noções de gênero, como é o caso das drag queens. A teoria queer
}

LGBTQIA+ population in terms of resistance and survival as a way of educating through mathematics for the understanding/constitution of political héxis, facing respect, manifestation, and emergence of gender subjectivities. Thus, in this theoretical article, we explain the concept of political héxis in connection with Queer Theory, discuss the sexgender system under a critical perspective and propose a didactic-pedagogical reflection on binary numbers (possible to be carried out in a mathematics class), in order to raise the understanding of the expansion of gender typologies in the world, in line with respect for differences. We conclude that if we increasingly propose mathematical activities that are liberating and that consider mathematics itself as a field of study dedicated to educating for citizenship and democracy, we will probably have a more humanitarian society.

Keywords: Gender; ASCII; Digital Technologies; Computational Thinking; Diversity.

\section{Estranhando o tema}

Estranhar é um verbo que denota variações de significado de acordo com a língua. Na língua portuguesa, por exemplo, estranhar significa achar estranho, fora do comum, algo ou alguém. Também, sugere que a pessoa não esteja cômoda com algo, ou seja, estranhando a cama, por exemplo. Pode ainda

defende que a orientação sexual e identidade de gênero não são resultado da funcionalidade biológica, mas de uma construção social. I = Intersexo - A pessoa intersexo está entre o feminino e o masculino. As suas combinações biológicas e desenvolvimento corporal - cromossomos, genitais, hormônios etc. - não se enquadram na norma binária (masculino ou feminino). Assexual- Assexuais não sentem atração sexual por outras pessoas, independente do gênero. Existem diferentes níveis de assexualidade e é comum que estas pessoas não veem as relações sexuais humanas como prioridade.,$+ \mathrm{O}+$ é utilizado para incluir outros grupos e variações de sexualidade e gênero. Aqui são incluídos os pansexuais, por exemplo, que sentem atração por outras pessoas, independente do gênero. (SILVA, 2020). 
ser sinônimo de espanto ou admiração quando se estranha um determinado comportamento, ou pode suscitar a ideia de esquiva e/ou fuga, principalmente quando se trata de crianças que estranham pessoas, as quais não estão acostumadas. Pode ainda significar uma ação de censura, repreensão, quando se estranha um ruído forte e possivelmente desagradável (DICIO, 2009). Entretanto, na língua espanhola conforme Diccionario de la Lingua Española (2021, tradução nossa $)^{2}$, estranhar pode assumir o significado de:

1. tr. Sentir a novidade de alguma coisa, faltando o que é de costume. Não dormi bem porque estranhei a falta da cama. 2. tr. Sentir saudades de alguém ou de alguma coisa, sentir sua falta. A criança chorou, estranhando a falta dos pais. 3. tr. Banir um país estrangeiro. U. t. c.prnl. 4. tr. Ver ou ouvir algo com admiração ou surpresa. U. m. c. prnl.5. tr. Censurar, repreender. 6. tr. pus. Separar, privar alguém do tratamento e da comunicação que teve com ele. U. $t$. c. prnl. 7. tr. Evitar, esquivar. 8. prnl. Recusar-se, negar-se a fazer alguma coisa.

Nesse sentido, o que nos chama a atenção para a diversidade de significados que se acentua é a ação de "sentir a novidade de alguma coisa, faltando o que é de costume". Ou seja, ao invés de nos dirigir aos sentidos de "fora do comum" ou de "não se sentir cômodo com algo ou alguém", como se esses fatos fossem pejorativos, trataremos do estranhar, neste texto, como a ação de sentir a novidade, sentir admiração, surpresa, falta de, como nos fala Dalla Vecchia (2012, p. 24):

\begin{abstract}
[...] não se trata de apenas explicitar algo que me "estranha" no sentido de um desconhecido, de um singular, de um acontecimento que foge à regra (BUENO, 1984). Trata-se também de algo que "extraño", isto é, levando em consideração o significado literal da palavra em espanhol, de algo de que
\end{abstract}

\footnotetext{
${ }^{2}$ extrañar Del lat. extraneāre 'tratar como aum extraño'. 1. tr. Sentir la novedad de algo, echando de menos loque resulta habitual. No he dormido bien porque extrañaba la cama. 2. tr. Echar de menos a alguien o algo, sentir su falta. Lloraba el niño extrañando a sus padres. 3. tr. Desterrar a país extranjero. U.t.c.prnl.4. tr. Ver u oír con admiración o extrañez a algo. U.m.c.prnl.5. tr. Afear, reprender.6. tr. p.us. Apartar, pr ivar a alguien del trato y comunicación que se tenía con él. U.t. c.prnl.7. tr. desus. Rehuir, esquivar.8. prnl. Rehusarse, negarse a hacer una cosa.
}

sinto falta (PARRA; MARQUES; DOLINSKY, 2008).

Logo, nosso estranhar a matemática toma forma naquilo que, a nosso ver, comumente não acontece na sala de aula. $\mathrm{Ou}$ seja, trata da educação matemática como área de pesquisa, de formação e de ação educacional preocupar-se mais com as minorias, com os excluídos, com os que são considerados fora da ordem, fora da regra e questionar: quem estipula a própria regra e o porquê o faz? Por que determinados grupos estariam fora, estariam externos a... excluídos? Que critérios definem isso, quem define e o que devemos fazer? Nossa afirmação parte do que Souza, Rodrigues e Figueiredo (2017, p.29) revelam:

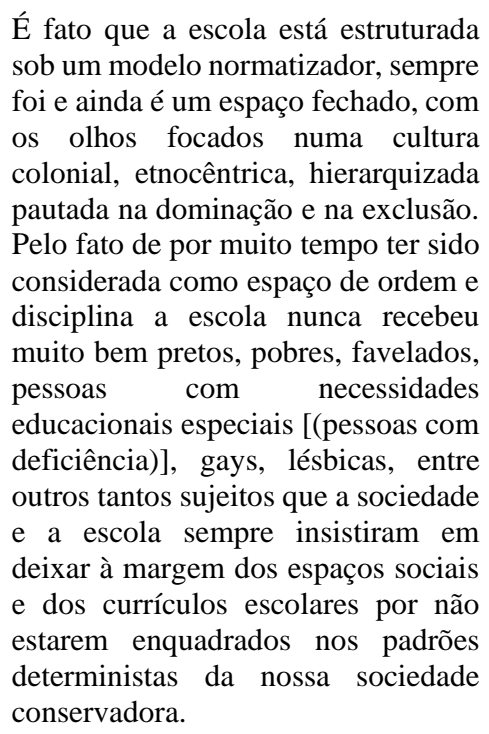

Também, consideramos o que nos diz Dubbs (2016, p. 1041, tradução nossa) $)^{3}$ : "Evidenciada pela lacuna de pesquisas que considerem estudantes queer, pesquisadores em educação matemática continuam a marginalizar as experiências dos jovens queer e a única resolução é centrar a experiência do estudante queer no contexto da matemática". Isto é, historicamente, o tratamento de aversão e rejeição a gays e lésbicas fez com que eles/elas/elus ${ }^{4}$ fossem

\footnotetext{
3 "Evidenced by the lack of research considering queer students, mathematics education researchers are continuing to marginalize the experiences of queer youth and the only resolution is to center the queer student experience in the mathematics context".

4 Esse texto trata de um posicionamento político de enfrentamento à discriminação de gênero e à "heterossexualidade compulsória" (BUTLER, 2020), isto é, à concepção social de que a heterossexualidade pode ser adotada de maneira independente das possíveis orientações sexuais de cada pessoa e aquelus que diferirem desta adoção são
} 
tratados/tratadas/tratades como "queers". Segundo Louro (2021, p.35):

\begin{abstract}
Queer pode ser traduzido por estranho, talvez ridículo, excêntrico, raro, extraordinário. Mas a expressão também se constitui na forma pejorativa com que são designados homens e mulheres homossexuais. Um insulto que tem, para usar o argumento de Judith Butler (1999), a força de uma invocação sempre repetida, um insulto que ecoa e reitera os gritos de muitos grupos homófobos, ao longo do tempo, e que, por isso, adquire força, conferindo um lugar discriminado e abjeto àqueles a quem é dirigido.
\end{abstract}

Não obstante, Louro (2021) discute a discriminação, a abjeção desta população LGBTQIA+ entrecruzadas à área de educação. A autora reflete sobre como podemos nos dirigir a uma perspectiva de um olhar "estranho", isto é, um olhar queer, pelo qual as categorias consideradas comuns, usuais, habituais, ditas "normais" do pensamento crítico-pedagógico também precisam urgentemente ser analisadas. Esta autora não busca estabelecer uma resposta ou verdade que seja coerente ou fiel a paradigmas (im)postos, no entanto, Louro (2021) se preocupa em transgredir, primeiramente desestabilizar, confundir qualquer designação que seja imposta, sob o que Bourdieu $(2009,2011)$ conceitua como habitus. No caso, entendemos como um habitus heteronormativo compulsório. Essa transgressão, então, revela os limites enfrentados nos espaços educativos, relativos ao modo como lidar com pessoas de diferentes gêneros, por exemplo.

O fato é, eu, você, todos, todas e todes precisamos educar e nos educar em termos sociais e políticos, ou seja, precisamos nos sentir incomodados com a fobia, com os insultos, com a maldade, com a crueldade, com a conotação pejorativa, com o descaso, com a necropolítica ${ }^{5}$, com as imposições, com o racismo, com o fascismo, com tantos outros "ismos" e provocar a compreensão do porquê o outro é considerado "estranho", que há a necessidade de resistência a padrões que

considerades desviades e depravades. Logo, o texto já é um marco de posicionamento político ao inserir, também, o gênero neutro, conforme Cassiano (2019), em sua escrita, pois empodera todes desviades e depravades. Não é uma tarefa fácil escrever com gênero neutro, mas é preciso começar.

${ }^{5}$ Conforme Mbembe $(2016$, p.146) “[...] propus a noção de necropolítica e necropoder para explicar as várias maneiras pelas venham a impor quem é ou não "estranho", por exemplo (ROSA, 2021, 2022). Principalmente, de quem pode ou não viver, pois, conforme Miranda (2020, p.132) aponta:

O Brasil é o país que mais mata pessoas LGBTI. A estimativa é de uma morte a cada dezesseis horas no período entre 2011 e 2018. Há ainda um alto grau de suicídio entre jovens LGBTI. E ultimamente o quadro vem se agravando: os dados do estado de São Paulo apontam para um aumento de $75 \%$ dos casos de LGBTfobia durante o período eleitoral de 2018.

Esses dados nos chamam a atenção, fundamentalmente, para a LGBTQIA+fobia enfrentada pela população originalmente encarada como queer, ou seja, a aversão, abjeção, rejeição, criminalização investida a esta população, principalmente, no Brasil. Nesse sentido, Hilton (2020, p.11, grifo nosso) ainda nos alerta que é no Brasil "Onde tem travesti morta à luz do dia, viado é espancado na rua, sapatão e homem trans sofrem estupro corretivo. Onde viver e envelhecer são privilégios."

Desse modo, neste artigo, queremos discutir como a educação matemática pode ajudar a sustentar a luta da população LGBTQIA+ em termos de resistência e sobrevivência enquanto forma de se educar pela matemática (ROSA, 2008; 2018). Isto é, assumimos que a compreensão/constituição da héxis política, frente ao respeito, à manifestação e à emersão das subjetividades de gênero nas aulas de matemática pode ajudar todos/todas/todes na formação conjunta de uma sociedade justa, democrática e fraterna. Logo, primeiramente discutiremos a concepção de héxis política e a sua relação com a Teoria Queer, que corrobora a concepção de estranhamento pedagógico ao que é declaradamente (im)posto como "normalidade". Em seguida, realizaremos uma reflexão didático-pedagógica sobre a abordagem de números binários que vem matematicamente a estranhar a ideia de gênero binário exclusivo, normal, correto. Não obstante, nos dirigimos sob um caminho

quais, em nosso mundo contemporâneo, armas de fogo são implantadas no interesse da destruição máxima de pessoas e da criação de "mundos de morte", formas novas e únicas da existência social, nas quais vastas populações são submetidas a condições de vida que lhes conferem o status de "mortos-vivos"”. 
específico, nos movimentamos, assim, rumo à héxis política na educação matemática, a qual necessita cada vez mais ser compreendida/constituída em cada espaço educativo.

\section{Héxis política e Teoria Queer}

Para tratarmos do conceito de héxis política, iniciamos discutindo o que assumimos por política. Assim, seguimos Bourdieu (2011, p.159) quando revela que "A política é o lugar, por excelência, da eficácia simbólica, acção que se exerce por sinais capazes de produzir coisas sociais e, sobretudo, grupos". Não obstante, Arendt (2020) afirma, usando as palavras de Tomás de Aquino, que o ser humano é por natureza político, ou seja, social. "Melhor que qualquer teoria elaborada, essa substituição incosciente do político pelo social revela até que ponto havia sido perdida a original compreensão grega da política" (ARENDT, 2020, p.28). Ou seja, tanto para Bourdieu (2011) quanto para Arendt (2020) há uma relação direta entre política e sociedade, a qual se mostra por meio da relação que cada ser humano demarca com algo que é comum a todos/todas/todes. Isto é, esse algo comum se faz com o outro/outra/outre, com o habitat e também com aquilo que ultrapassa a vida privada. Mesmo com essa extrapolação, persiste a relação de poder que estrutura, delimita, orienta, regula. Logo, nos resta questionar essa relação de poder, ou seja, nos cabe ir além para poder compreender a política por meio do que conceitua Arendt (2002), pois, para ela, a política toma por base a pluralidade das pessoas em prol da liberdade coletiva e individual. Para a autora, a política está na esfera do entre, se apresenta como chance e espaço para a liberdade. Esta, então, acontece pelo agir, pela tomada de iniciativas e pela possibilidade de constituir "um novo começo".

Entretanto, conforme Bourdieu (2011), a política como campo de luta não é e nem deve ser consensual, em sua completude. Ele, desse modo, assume a luta como proposição, assume a liberdade de capital simbólico em seu âmago, pois, caso contrário, a liberdade estaria fadada ao totalitarismo, se não houvesse crítica, se não houvesse oposição e tudo fosse exigido sem condições e nem, tampouco, concessões. Não obstante, para Bourdieu (2011, p.185), "O campo político é pois o lugar de uma concorrência pelo poder que se faz por intermédio de uma concorrência pelos profanos ${ }^{6}$, ou melhor, pelo monopólio do direito de falar e de agir em nome de uma parte ou da totalidade dos profanos".

O campo político é compreendido como o espaço social onde a luta acontece pelo discurso e pela ação, isto é,

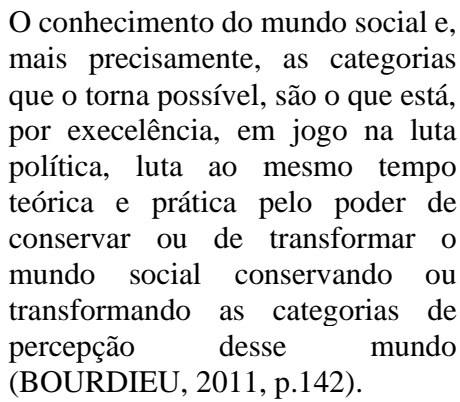

O conhecimento do mundo social e, mais precisamente, as categorias que o torna possível, são o que está, por execelência, em jogo na luta política, luta ao mesmo tempo teórica e prática pelo poder de conservar ou de transformar o mundo social conservando ou transformando as categorias de percepção desse mundo (BOURDIEU, 2011, p.142).

Desse modo, a população LGBTQIA+ e suas comunidades, muitas vezes organizadas em guetos de força e representatividade, cada vez mais se inserem nessa luta política, pois, inclusive na academia, teorizam sobre suas realidades, suas humanidades e cientificam seus modos de ser e agir. A luta LGBTQIA+ não é uma luta identitária, mas uma luta política. Mesmo que parte da população, por meio do senso comum, acredite que essa luta é identitária, expressando a falta de compreensão do todo, uma vez que manifestam em seus discursos o desconhecimento de cada papel social da sigla que representa esta população, assim como, expressam espanto quando se surpreendem que a sigla a cada dia se torna maior, esta luta não é identitária. Lésbicas, Gays, Bissexuais. Transgêneros, Transsexuais, Travestis, Queers, Questinando-se, Intersexos, Agêneros, Assexuais, Aliados/aliadas, Curiosos/curiosas, Pansexuais, Polisexuais, Familiares, 2 (dois espíritos), Kint e + (mais) tudo aquilo o que puder e quiser vir, se estabele como a atual sigla de representatividade LGBTQIA+ (LGBTQIA+, 2021) e cada vez mais se apresenta como posicionamento para o

\footnotetext{
${ }^{6}$ Profanos é o termo usado por Bourdieu (2011) para se referir a classe dos operários, oprimidos, subjugados, ou seja, os que não detém de um código erudito.
} 
reconhecimento.

Embora erroneamente se diga que é uma "sopa de letrinhas", ignorando os movimentos teóricos provenientes de pesquisas realizados pelas Ciências Humanas e Sociais Aplicadas, gênero, sexo e sexualidade são temáticas que há muito tempo tem sido estudadas e que ainda precisam de muita desmistificação. Por exemplo, é importante que se saiba que há diferença entre Transgêneros e Travestis e que esta perpassa uma postura política frente a historicidade do termo. Isto é, a diferença não está no órgão sexual, não se trata do "falo" que foi ou não retirado, o que se apresenta é uma atitude política. Como nos afirma Butler (2020, p. 217), "O molde e a forma dos corpos, seu princípio unificador, suas partes combinadas são sempre figurados por uma linguagem impregnada de interesses políticos". Assim, Transsexuais, Transgêneros e Travestis são identidades femininas, mas, sob uma luta característica, em especial por parte das Travestis, as quais se assumem Travestis sob a mesma ênfase dada ao termo queer, isto é, dando valor ao sentido a ser atribuído a ele, buscando a desestigmatização do próprio termo.

A luta política é dada pelo fato de que quando um corpo trans aparece e este corpo é periférico, é prostituído, foi vítima de violência, de injúria, foi alvo de chacota, automaticamente este corpo é denotado como Travesti e isto, implicitamente ou explicitamente, implica na ideia de algo sujo, mulambo, drogado, que não serve, que não presta. Ao mesmo tempo, quando esta mulher trans é aprovada em uma universidade, ocupa um papel social de destaque, por exemplo, advocacia, medicina, licenciatura, representa a ONU, o que se mostra é a mulher trans, não tratam da travesti. Por isso, quando uma trans se define Travesti, ela o faz consciente de sua luta política, ela defende sua classe, pois a distinção nada mais é do que um recorte de raça e classe, corpos racializados e subalternizados são travesti, corpos em melhor posição social são trans e mesmo que não estejam livres dos precoceitos vividos, já possuem muitas camadas de ideologia sobre

\footnotetext{
7 Pathés ou Pathós - Tipo de experiência humana, ou sua representação em arte, que evoca dó, compaixão ou uma simpatia compassiva no espectador ou leitor: o páthos de "Os Retirantes" de Portinari. (Cf. patos.). (DICIO, 2009).
}

eles (LGBTQIA+, 2021).

Por conseguinte, a luta em se conservar ou transformar o mundo social, em se respeitar as pessoas, em não estigmar qualquer pessoa que seja, parte de diferentes posições, disposições, posturas políticas que se apresentam em diferentes graus e de diferentes formas. Logo, o conceito de héxis política perfaz justamente a lacuna teórica que não suplanta as diferenças, graus e formas de disposição à política. Isto é,

\begin{abstract}
Na Ética Nicomaquéia, Aristóteles define a virtude de caráter como 'uma disposição (héxis) envolvendo escolha, consistente em um meio termo (que é relativo a nós), sendo este determinado por um princípio racional, e por um princípio racional que o homem de sabedoria prática determinaria (EN II.6 1106b36- 37).' $\mathrm{O}$ que nos interessa observar nesta passagem é que a virtude é definida como uma hexis e uma hexis é uma qualidade que diz respeito ao modo (bom ou mau) pelo qual agimos quando somos afetados pelas pathés ${ }^{7}$ (EN II.5 1105b25-26) (WAGNER, 2018).
\end{abstract}

Não obstante, conforme Hobuss (2010, p. 225, grifo do autor), "A disposição (hexis) é definida como: diathesis psichês kathê hên poioi tines legometha (estado da alma que nos faz qualificar de tal ou tal maneira)", ou seja, possuir uma disposição, envolvendo escolha, para qualificar a política, uma disposição à própria política, como fator proeminente da democracia, como disposição a dar voz a todos/todas/todes.

Essa voz precisa ser fundamentada, cabe debatermos sobre um postura consciente do que diz e defende. Logo, é imprescindível que a matemática a ser ensinada também preveja as diferenças, que se situe em relação à geração que cresce com celulares, tablets e computadores a sua volta, e que, da mesma forma, eduque matematicamente os/as/es estudantes em um contexto democrático de acolhimento, escuta e de voz dada a todos/todas/todes. Mas, que além disso, assuma uma héxis política pelo bem comum, do social, na qual a matemática ensinada seja antiracista, antimisógena, anti-ageísta ${ }^{8}$, anti-

\footnotetext{
${ }^{8}$ Conforme Goldani (2010, p. 385) “[...] o viés estereotipado e frequentemente negativo descrevendo grupos de idade, em
} particular adultos mais velhos, é denominado 'ageismo"'. 
homofóbica, anti-transfóbica, etc. Que ela se torne queer, que estranhe, que faça pensar e se desgrude da equivocada imagem de neutralidade e de preocupação exclusiva com números e fórmulas.

Assim, a educação para a conscientização, ou seja, compreensão e/ou constituição de héxis política em relação às minoriais e tudo o que as envolve é primordial, pois necessitamos nos responsabilizar pelo/pela/pele outro/outra/outre e ter uma disposição em relação à posição de respeito frente à pluralidade de seres humanos, mesmo que particularmente isso venha trazer prejuízos individuais.

A héxis política é disposição a, é postura que assume como premissa o pluralismo político, a igualdade em termos de participação política e, consequentemente, a liberdade e o respeito às diferenças. Parte do princípio democrático, pois contraria a perspectiva de uma sociedade definida por um único grupo ou por uma só pessoa (ditadura ou totalitarismo Arendt (2003)). Nesse sentido, perfaz uma disposição ao novo, ao estranho, ao que falta, às minorias e vai além, pois, pode e se debruça, de modo reflexivo, sobre a pedagogia queer, a qual utiliza o termo "queer" como luta política e de intensificação da transformação de sentido dado a este termo.

De insulto à elogio para a comunidade LGBTQIA+, o termo queer invade a academia e admite o estranhamento como algo necessário, inovador, provocativo e que merece respeito, inclusive teórico. $\mathrm{Na}$ área de educação matemática, por exemplo, Dubbs (2016) argumenta sobre a necessidade de um teor mais "queer" na própria educação matemática (fator que já acompanha disciplinas das humanas como geografia, biologia e inglês há mais de uma década), pois é um modo de desmarginalizar a juventude LGBTQIA+ propiciando um novo espaço a esses/essas/essus jovens. Esse autor argumenta sobre a importância da matemática na sociedade, porém admite que a masculinidade heteronormativa atribuída a esta disciplina torna-se opressora a cada estudante queer (entendendo esse/essa/essu estudante

\footnotetext{
9 "To work within the terms of gay and lesbian theories, then, allows for the consideration of two kinds of pedagogical stakes. One has to do with thinking ethically about what discourses of difference, choice, and visibility mean in classrooms, in pedagogy, and in how education can be thought about. Another has to do with thinking through structures of disavowal within
}

pertencente ao grupo LGBTQIA+). Apesar de, muitas vezes, a matemática ser caracterizada como imparcial, ela nada tem de imparcial ou neutra ao ser utilizada para a guerra, como fator de poder ou vinculada ao gênero masculino heteronormativo, ou mesmo admitida como "neutra" frente à questão de gênero e sexualidade, por exemplo. $\mathrm{O}$ fato de não considerar a sexualidade acaba privilegiando uma posição de heterossexualidade compulsória, pela qual os/as/es estudantes queers acabam se afastando. Dubbs (2016), então, sugere em seu estudo possibilidades de pesquisa em educação matemática por meio de um currículo queer, uma pedagogia queer, ou seja, possibilitando uma nuance queer para os espaços educativos matemáticos.

Segundo Britzman (1995, p.152, tradução nossa) ${ }^{9}$ :

Trabalhar nos termos das teorias gays e lésbicas, então, permite a consideração de dois tipos de desafios pedagógicos. Trata-se de pensar eticamente sobre o que significam os discursos de diferença, escolha e visibilidade nas salas de aula, na pedagogia e em como a educação pode ser pensada. Outra tem a ver com pensar em estruturas de recusa dentro da educação, ou seja, as recusas sejam curriculares, sociais ou pedagógicas envolvem uma percepção traumática que produz o sujeito da diferença como uma ruptura, como fora à normalidade. Diante desses desafios, uma espécie de discurso universalizante [é] [...] - o que a educação precisa aprender com as [...] demandas políticas de quem vive nos limites sexuais ou além?

Questionar a aprendizagem que a educação pode ter com aqueles/aquelas/aquelus que vivem nos limites (fronteiras) ou ultrapassam esses "limites sexuais" impostos, denotados, construídos, normatizados já é um primeiro ensejo de estranhamento à própria pedagogia heteronormativa, ou seja, uma primeira nuance da própria pedagogia queer. Questionar a própria pergunta ou a indução clássica a uma resposta heteronormativa, por exemplo, já se

education, or the refusals whether curricular, social, or pedagogical engage a traumatic perception that produces the subject of difference as a disruption, as the outside to normalcy. Given these stakes sort of universalizing discourse [...] -what does education need to learn from the [...] political demands of those who live at or beyond the sexual limits?" 
torna um movimento de estranhamento. Isto é, a pedagógica queer prima pelo ato de se questionar a resposta e a "naturalidade" da resolução de um problema do tipo que é apresentado no Blog do ENEM (2021, grifo do autor):

Numa sala existem 3 garotas (Adriana, Beatriz e Cleide) e 2 rapazes (Rodrigo e Sandro). Quantos casais diferentes podemos formar com essas 5 pessoas?

Resolução: - Para formarmos um casal precisamos agrupar 1 homem e 1 mulher, isto é, precisamos tomar uma decisão d1 que consiste na escolha de um homem e tomar uma decisão d2, que consiste na escolha de uma mulher.

- A decisão d1 pode ser tomada de 2 maneiras diferentes (existem 2 homens);

- A decisão $\mathrm{d} 2$ pode ser tomada de 3 maneiras diferentes (existem 3 mulheres).

Logo, o número total de casais é 2.3 $=6$.

Por que para se formar um casal é preciso agrupar "um homem e uma mulher"? A resposta já não parte de uma falácia? A resposta, então, está certa? Que matemática é essa? Que interpretação matemática é essa? Nessa perspectiva, Louro (2021, p.60) revela que:

A ideia é pôr em questão o conhecimento (e o currículo), pôr em questão o que é conhecido e as formas como chegamos a conhecer determinadas coisas e a não conhecer (ou a desconhecer) outras. Não se trata, propriamente, de incorporar ao currículo (já superpovoado) um outro sujeito (o queer), mas sim, mais apropriadamente, de pôr em questão a ideia de que disponha de um corpo de conhecimentos mais ou menos seguro que deva ser transmitido: além disso, pôr em questão a forma usual de conceber a relação professorestudante-texto (texto aqui tomado de forma ampliada).

A pedagogia queer, então, toma por base o estranhamento, isto é, o colocar em suspeição aquilo que é (im)posto sem que haja

\footnotetext{
10 "I think of Queer Theory as provoking terms of engagement that work both to recuperate and to exceed the stereotypes that contain and dismiss gay and lesbian subjects. But as a doubled gesture, Queer Theory signifies improper subjects and improper theories, even as it questions the very grounds of identity and theory. Queer Theory occupies a difficult space between the
}

um questionamento a priori. Aquilo que é normatizado, normalizado, sob critérios que privilegiam uns/umas/unes em detrimento de outros/outras/outres. Mais que isso, busca transgredir formas de pensar que "enquadrem", rotulem, classifiquem em prol do estabelecimento da binaridade entre aqueles/aquelas/aquelus que merecem e os que não, entre os/as/es que se enquadram à norma e os/as/es que não, entre os/as/es detentores/detentoras/detentories do poder e os/as/es que são excluídos/excluídas/excluídes naturalmente. Assim, a pedagogia queer na educação matemática precisa provocar a discussão dessa binaridade, também matematicamente. Por exemplo, comparar, mensurar, relacionar, discutir a igualdade e inequidade, as diferentes possibilidades frente ao que é (im)posto, são formas de se educar pela matemática, democraticamente. Dessa forma,

Penso na Teoria Queer como termos provocativos de engajamento que funcionam tanto para recuperar quanto para superar os estereótipos que contêm e rejeitam sujeitos gays e lésbicos. Mas como um gesto duplo, a Teoria Queer significa sujeitos impróprios e teorias impróprias, mesmo quando questiona os próprios fundamentos da identidade e da teoria. A Teoria Queer ocupa um espaço difícil entre o significante e o significado, onde algo queer acontece ao significado à história e aos corpos - e algo queer acontece ao significante - à linguagem e à representação. Se alguém ouve a Teoria Queer como figurativa ou literal, como uma provisão ou como uma condição, pode depender do que pode ser imaginado quando "queer" é trazido para a "teoria" e quando "teoria" é trazida para o "queer". O termo é desafiador, mas pode ser ouvido como acusatório. Mas o "queer", como a "teoria", na Teoria Queer não depende da identidade do teórico ou daquele que se envolve com ele. Em vez disso, o queer na Teoria Queer antecipa a precariedade do significado: os limites dentro de suas convenções e regras, e as maneiras pelas quais essas várias convenções e regras incitam desempenhos subversivos, citações e inconveniências (BRITZMAN, 1995, p.152, tradução nossa $)^{10}$.

signifier and the signified, where something queer happens to the signified - to history and to bodies - and something queer happens to the signifier- to language and to representation. Whether one hears Queer Theory as figurative or as literal, as a provision or as a condition, may depend on what can be imagined when "queer" is brought to bear upon "theory" 
A incitação aos desempenhos subversivos, ao questionamento às convenções e regras, implica no estranhar o currículo heteronormativo, o qual é dado como pronto acabado, "normal". Também, vai além de querer basicamente incluir os/as/es estudantes LGBTQIA+ nesse currículo "normal", uma vez que, por acaso, alguém perguntou se eles/elas/elus desejam ser "incluídos"? Normatizados? Normalizados? Para Louro (2021, p.47-48):

Uma pedagogia e um currículo conectados à teoria queer teriam de ser, portanto, tal como ela, subversivos e provocadores. Teriam de fazer mais do que incluir temas ou conteúdos queer; ou mais do que se preocupar em construir um ensino para sujeitos queer. [...] Vistos sob essa perspectiva, uma pedagogia e um currículo queer "falam" a todos e não se dirigem apenas àqueles ou àquelas que se reconhecem nessa posição-desujeito, isto é, como sujeitos queer.

Nesse sentido, concordamos com a subversão e provocação ocasionados pela própria pedagogia, assim como, entendemos como importante que essa pedagogia vá além e que seja para todos/todas/todes. Entretanto, alertamos para que não se confunda este "para todos/todas/todes" com uma posição generalizadora que acabe "esquecendo", ou seja, não voltando as atenções principalmente para os/as/es sujeitos queers, isto é, esquecendo a origem da própria teoria. A nosso ver, a própria ideia de "ter que ser assim" ou "ter que ser assado" deve ser colocada em suspeição. As nuances da subversão, dos questionamentos e compreensão/constituição de héxis política abarcam uma paleta de cores com número imensurável, ou como Louro (2021, p. 65) revela "Há coisas e há sujeitos que podem ser pensados no interior de uma cultura e outros que são impensáveis, e são impensáveis porque não se enquadram numa lógica ou num quadro admissíveis àquela cultura, naquele momento". Trabalhar pelos/pelas/peles sujeitos queers e demais

and when "theory" is brought to bear upon "queer." The term is defiant but can be heard as accusatory. But the "queer", like the "theory," in Queer Theory does not depend on the identity of the theorist or the one who engages with it. Rather the queer in Queer Theory anticipates the precariousness of the signified: the limits within its conventions and rules, and the ways in which these various conventions and rules incite subversive performances, citations, and inconveniences". excluídos também se torna uma ação de estranhamento frente a uma pedagogia do CIStema $^{11}$, o qual é eurocêntrico e heteronormativo.

Assim, a concepção queer carrega consigo a ideia de transformação e essa ideia já assume por si só uma perspectiva queer, pois o próprio "trans" da palavra é um prefixo que sustenta uma situação ou ação que vai "além de". Ou seja, além de formar é transformar, além de ascender é transcender. Logo, é importante que cada estudante queer que foi ofendido/ofendida/ofendide como "estanho/estranha/estranhe" transcenda e transforme a ofensa em elogio, que consiga entender que como ele/ela/elu é, ou deixa de ser, importa somente a ele/ela/elu, e que isso não o/a/e faz ser menor/menos que ninguém. Assim, é importante que a educação matemática assuma sua responsabilidade social, de forma a colocar em discussão sua própria postura em relação à manutenção de um modelo heteronormativo de aula de matemática. Também, a educação matemática precisa estranhar qualquer disposição a ficar supostamente "neutra/neutro" em relação ao papel de educar pela matemática frente a questões de gênero e sexualidade. Logo, passamos a próxima seção trazendo ao debate a binaridade em uma perspectiva matemática de sala de aula.

\section{Números Binários: história, diversidade e possíveis "estranhamentos" em aula}

\section{Conforme Mendes (2017, p.41)}

\begin{abstract}
O sistema binário é um sistema de numeração posicional que utiliza todas as características do sistema de numeração decimal (base 10), tomando como base o 2, cada algarismo, 0 ou 1 , a depender de sua posição, passa a representar o seu valor absoluto multiplicado pela potência de 2 relativa à posição, enumerados da direita para a esquerda.
\end{abstract}

Assim, a ideia de binaridade

\footnotetext{
11 "CIStema" escrito propositalmente assim por Hilton (2020), remete a palavra "sistema" a uma concepção de sociedade significativamente cisgênera (condição da pessoa em identificarse com a identidade de gênero correspondente ao que lhe foi atribuído/designado no nascimento) e assume a expulsão, a opressão e a eliminação de corpos que não se enquadram à concepção heterocisnormativa.
} 
perpassada diz-se do que é composto de duas unidades ou dois elementos, dois, e somente dois, algarismos, no caso do sistema binário, o 0 (zero) e o 1 (um), assim como, matematicamente também pode significar uma relação que pode ligar duas grandezas. Por conseguinte, na Música diz-se do compasso de dois tempos. Também, nas Ciências Sociais, esta concepção é muito utilizada devido a sua apropriação à ação humana. Conforme Bourdieu (2020, p. 21):

\begin{abstract}
Arbitraria em estado isolado, a divisão das coisas e das atividades (não necessariamente sexuais) segundo a oposição entre o masculino e o feminino recebe sua necessidade objetiva e subjetiva de sua inserção em sistema de oposições homólogas, alto/baixo, em cima/embaixo, na frente/atrás, direita/esquerda, reto/curvo, seco/úmido, duro/mole, temperado/insosso, claro/escuro, fora (público)/dentro (privado) etc., que para alguns corresponde a movimentos do corpo (alto/baixo//subir/descer//fora/dentro //sair/entrar).
\end{abstract}

Não obstante, a binaridade também é muito evidenciada em relação a questões de gênero. Conforme Butler (2020, p. 26), “[...] mesmo que os sexos pareçam não problematicamente binários em sua morfologia e constituição (ao que será questionado), não há razão para supor que os gêneros também devam permanecer em número de dois", embora essa relação é a que se apresenta em termos de dominação, ainda nos dias atuais.

Nas Ciências da Computação, por sua vez, o sistema binário é utilizado para representar informações. Isto é, chama-se binário pelo fato de utilizar dois dígitos distintos. Cada zero ou um é chamado de bit (dígito binário) e, por conseguinte, um bit é normalmente representado na memória principal do computador por um transistor, que pode estar ligado ou desligado, ou um capacitor, que pode estar carregado ou descarregado (BELL; WITTEN; FELOWS, 2011).

A invenção dos números binários já foi atribuída aos nativos da Mangareva, que é uma pequena ilha situada na Polinésia Francesa (BENDER; BELLER, 2013), também há a

12 "Car ici, c'est comme si on disait, par exemple, que 111, ou 7 , est la somme de quatre, deux et un, et que 1101, ou 13 est la somme de huit, quatre et un. Cette propriété permet aux possibilidade de um primeiro registro com o povo indiano no século 5 A. C. (VAN NOOTEN, 1993), além do fato que os antigos chineses utilizaram números binários no texto I Ching, que é considerado o mais antigo livro da China, datado séculos antes de Cristo (IFRAH, 2001). Em todos os casos, os números binários, mesmo sem um sistema de notação, datam anteriores à demonstração das vantagens do sistema binário para cálculos por Leibniz, já em 1703 (BENDER; BELLER, 2013).

Mais do que a própria origem dos números binários, o que nos cabe aqui é estranhar a história oficial, é questionar o quanto a documentação do sistema numérico binário moderno realizada por Gottfried Leibniz no século XVIII em seu artigo "Explication de l'Arithmétique Binaire"(LEIBNITZ, 1703) garante a originalidade da ideia, a autoria da descoberta, a atribuição de valor ao conhecimento produzido. O sistema binário de Leibniz, então, utilizou 0 e 1 , assim como é o sistema numérico binário que conhecemos atualmente. Este sistema, já nos povos da Polinésia, India e China, favoreceu às atividades cotidianas como a contagem de animais, frutas, hortaliças. Posteriormente, em 1854, George Boole (matemático britânico) publica um trabalho maduro sobre Lógica (BARNETT, 2011) que seria reconhecido como Álgebra Booleana. Esse sistema tornou-se de grande importância para o desenvolvimento do sistema binário, particularmente sua aplicação em situações de avanço tecnológico.

Devido ao sistema binário, avanços tecnológicos e da informática foram possíveis (IFRAH, 2001). Como aponta Leibnitz (1703, p. 86 , tradução nossa) ${ }^{12}$, o sistema numérico binário, ou seja, de base 2, possui grande utilidade para cálculos, uma vez que confome Figura 1, ele afirma:

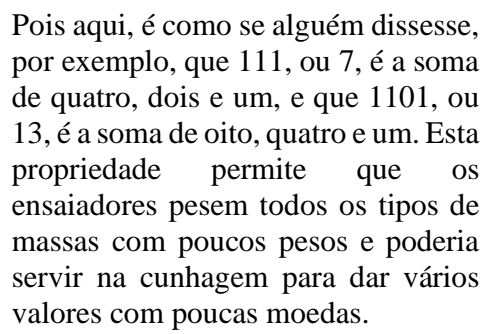

Figura 1: Figura sobre argumento de Leibnitz

essayeurs de peser toutes sortes de masses avec peu de poids et pourrait servir en monnayage à donner plusieurs valeurs avec peu de pièces". 


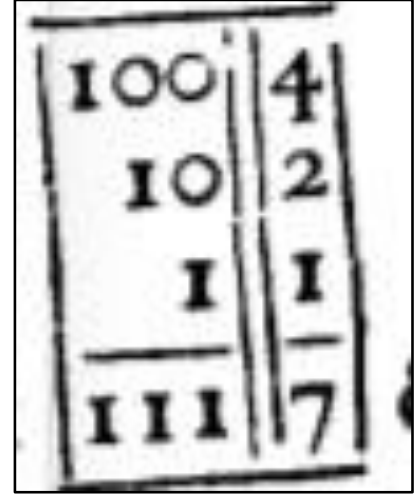

Fonte: Leibnitz (1703, p.86)

Além disso, para Leibniz, um sistema binário também contribuiria para que a pessoa não precisasse decorar qualquer tabuada de adição e multiplicação, por exemplo, pois, uma vez que existe apenas os dígitos 0 e 1 , a contagem no sistema binário se torna intuitiva, respeitando a seguinte forma: $0,1,10,11,100$, $101,111,1000,1001,1011,1111$ e assim sucessivamente. A intuição seria um benefício, entretanto, as representações numéricas cada vez seriam mais longas. Também, a troca de um sistema decimal por um binário, por exemplo, estaria atrelada à dificuldade de mudança de um sistema pelo qual estamos acostumados (ou seja, já sabemos de cor como contar por dez) por um sistema que precisaríamos aprender novamente, ou seja, um sistema estranho.

Para passar de um sistema a outro, se faz necessária a compreensão da conversão de um número binário para um decimal e viceversa. Tomando, por exemplo, o número binário 10110, sua conversão para o sistema decimal é estabelecida pela adição das multiplicações de cada algarismo, da direita para a esquerda, por potências de 2 , em ordem crescente, iniciando na potência $2^{0}$. Isto é, da direita para a esquerda o primeiro algarismo que é o 0 (zero) multiplica $2^{0}$, o segundo que é 1 (um), multiplica $2^{1}$, o terceiro que também é 1 (um) multiplica $2^{2}$, o quarto que é 0 (zero), multiplica $2^{3}$ e o quinto que é 1 (um) multiplica $2^{4}$. O cálculo se estabelece como:

$$
\begin{aligned}
& 10110=1 \cdot 2^{4}+0 \cdot 2^{3}+1 \cdot 2^{2}+1 \cdot 2^{1}+0 \cdot 2^{0}=16 \\
& +0+4+2+0=22
\end{aligned}
$$

Assim, 10110 na base 2, também denotado como $10110_{2}$, é equivalente a 22 na base 10 , ou $22_{10}$. Usamos um índex com o valor da base para diferenciá-los. Esses números, então, são equivalentes, $10110_{2}=22_{10}$, diferindo somente pela forma que são escritos, ou seja, em bases distintas, o que significa que ambos são constituídos pela adição de multiplicações entre os algarismos e as potências da mesma base que seu índex indica. No caso dos números do sistema decimal, o 45 , por exemplo, nada mais é do que $4 \cdot 10^{1}+5 \cdot 10^{0}$. Genericamente, um número $\mathrm{N}$ qualquer pode ser escrito como o somatório de cada algarismo $\left(a^{\mathrm{n}}\right)$, multiplicado por $2^{\mathrm{n}}$, onde $\mathrm{n}$ é a posição do último algorismo, sendo representado por: $\mathrm{N}=a_{\mathrm{n}} \cdot 2^{\mathrm{n}}+a_{\mathrm{n}-1} \cdot 2^{\mathrm{n}-1}+a_{\mathrm{n}-2} \cdot 2^{\mathrm{n}-2}+\ldots+a_{2} \cdot 2^{2}+$ $a_{1} \cdot 2^{1}+a_{0} \cdot 2^{0}$. Assim, também, um número $\mathrm{N}$ em uma base qualquer é dada por $(\mathrm{N}) \mathrm{b}$, onde $\mathrm{b}$ denota a base de representação. $\mathrm{N}=a_{\mathrm{n}} \cdot \mathrm{b}^{\mathrm{n}}+a_{\mathrm{n}}$ $1 \cdot \mathrm{b}^{\mathrm{n}-1}+a_{\mathrm{n}-2} \cdot \mathrm{b}^{\mathrm{n}-2}+\ldots+a_{2} \cdot \mathrm{b}^{2}+a_{1} \cdot \mathrm{b}^{1}+a_{0} \cdot \mathrm{b}^{0}$

Para efetuarmos a conversão inversa, isto é, do sistema decimal para o binário, pegamos o número escrito no sistema decimal e o dividimos por 2, visto que é a base do sistema binário, e reservamos o resto da divisão, o qual sempre será 0 ou 1. Em seguida dividimos o quociente também por dois e reservamos o resto, ou seja, repetimos o processo até que o quociente da divisão seja o número um. Dessa forma, o número binário será a junção dos restos, do último ao primeiro, enquanto algarismos. Exemplificando, utilzamos a conversão do 22 (mesmo número do exemplo anterior) e, assim, temos:

Figura 2: Conversão do sistema decimal para o binário.

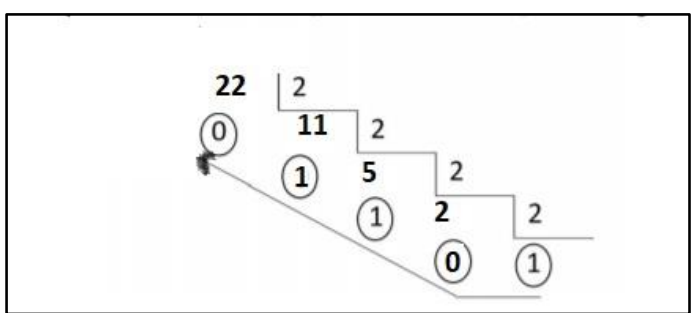

Fonte: o autor

Até o momento, apresentamos o que é sistema binário, a divesridade de áreas que o abrangem, aspectos históricos e o modo de conversão para o sistema decimal e vice-versa. No entanto, cabe-nos ainda e principalmente travar a discussão sobre a luta da população LGBTQIA+ em termos de resistência e sobrevivência articulando essa questão ao sistema binário. Assim, partimos de Rossini (2018, p.14), que afirma que: 
Até o século XVIII, o corpo masculino e feminino era centrado no modelo de isomorfismo, ou seja, havia um único modelo para representar ambos. Homens e Mulheres eram classificados conforme seu grau de perfeição metafísica, os dois corpos eram considerados semelhantes, o corpo feminino possuía os mesmos membros que o masculino, porém, virados para dentro. A diferença se dava devido ao calor vital recebido na gestação e a causa final era o corpo masculino, perfeito. A mulher era vista como um corpo imperfeito comparado ao homem, este que era o modelo do sexo único. A vagina equivalia ao pênis (interno), os lábios ao prepúcio, o útero ao escroto e os ovários aos testículos. [Não obstante,] [...] Por volta do final do século XVIII, a anatomia e a fisiologia estabeleceram um saber biológico que justificava a diferença sexual em espécie, não mais em grau. Os escritores estavam determinados a provar a diferença entre os sexos de forma que a biologia passaria a justificar a ordem social. Patrick Guedes, professor de biologia, utilizou da fisiologia celular para explicar o fato de as mulheres serem mais passivas em relação aos homens. A partir da análise de cavalos marinhos, ele observou que a fêmea tinha a função de armazenar energia e o macho de despender. Os saberes acumulados pelos biólogos passaram então a justificar a ordem social a partir da diferença baseada no organismo e não mais em uma realidade metafísica.

Nesse sentido, a alteração de uma estrutura única, isomórfica, para uma estrtura binária ocorre segundo Laqueur (2001) por uma questão epistemológica e outra política. Em termos epistemológicos, o corpo começa a ser regido/justificado pela Ciência e não mais por um Deus. Torna-se especificamente analisado e compreendido pela fisiologia e anatomia. Em termos políticos, a competição entre sexos começou a se fazer presente, principalmente, em relação à revolução industrial e, consequentemente, à divisão sexual de trabalho nas fábricas. Historicamente, como nos relata Bourdieu

\footnotetext{
${ }^{13}$ Assumimos que a atividade pode ser adaptada/modificada para outros anos, sob o cuidado inicial da observação e reconhecimento da turma. Não desejamos que ao invés de provocar possível amadurecimento e compreensão/constituição de héxis política por parte dos/das/des estudantes, qualquer
}

(2020), a dominação masculina sempre reinou, mesmo quando havia a concepção de estrutura única, pois nesta a mulher era considerada "o homem que não deu certo". Com a ascenção da Ciência e do capital, a binaridade se torna importante, no entanto, a questão de dominação masculina não é reduzida. Tanto não é que carrega consigo a relação de dominação frente à homossexualidade masculina, diferenciando, inclusive, a performance sexual de cada um como ativa ou passiva e esta última, sendo correlacionada à performance feminina e, por isso, comprendida como inferior. Nessa visão binária, inclui-se a responsabilidade das instituições em termos de exclusão daquelas/daquelas/daquelus que não se enquadram exclusivamente em nenhuma das duas posições, como se só houvesse no mundo 0 (zero) e 1 (um), macho e fêmea, masculino e feminino, extremamente definidos.

A ideia de discutir números binários em sala de aula, então, além de suscitar todos os pontos que levantamos, principalmente, nas Ciências da Computação a representação de informações, elenca uma particularidade de estranhamento que a matemática pode sustentar: a discussão de sexualidade e gênero. A partir de descoberta e estranhamento, sugerimos uma atividade-matematica com números binários. Assim, nosso processo didático-pedagógico começaria com algumas questões a serem propostas a uma turma do Ensino Médio, por exemplo ${ }^{13}$ : a) Você sabe o que significa o prefixo bi? Pode comentar? Tem a ver com títulos do futebol/voleibol/outro esporte em termos de campeonatos, por exemplo? (Lembramos que cada professor/professora/professorie sabe quais perguntas deve fazer para fomentar a reflexão de um tema de interesse, logo, essas perguntas configuram somente exemplos que nós faríamos). b) Você sabe o que significam as palavras binário/binária/binaridade? Já ouviu falar? Tem alguma noção do que deve ser? (A investigação em sites de busca é possível e recomendada). c) Você sabe o que são números binários? Para que servem?

Após discussão fomentada a respeito do sistema de posição binária, por meio de investigação, seria importante tratar sobre as

\footnotetext{
destes/destas/destus se sinta objetificado, seja ridicularizado/ridicularizada/ridicularizade pelos/pelas próprios/próprias colegas
} 
transformações de um sistema a outro, sobretudo articulando à discussão sobre o sistema de posição decimal (sugere-se pesquisar/falar/suscitar investigação sobre sistemas computacionais, representação de informação na informática, entre outras relações possíveis e imagináveis). Além disso, apresentamos (figura 3) uma atividade a ser desenvolvida, na ordem que preferir, que achar que a turma pode estar suficientemente provocada a responder, ou seja, como início de dicussão ou mesmo após instrução de conversão de números, de uma base 2 para uma base 10 e vice-versa:

Figura 3: Atividade-matemática de números binários

\begin{tabular}{|c|c|}
\hline Tente decifrar os se & eros codificados \\
\hline 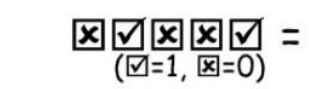 & $\begin{array}{l}\Leftrightarrow<1, \$=0) \\
(\otimes=1, \infty\end{array}$ \\
\hline 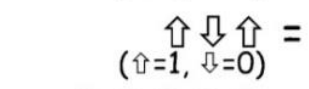 & $\underset{(+=1,}{\mathbf{x}=0)}=$ \\
\hline$\bigcirc \underset{(\odot=1, \bigcirc=0)}{\bigcirc \bigcirc \bigcirc}=$ & $\cup \cup \cup \cup \cup=$ \\
\hline$\left(\Theta=1, \frac{\sigma}{\Delta=0)}=\right.$ & $\nabla=0$ \\
\hline $\begin{array}{r}(0) \\
(\odot=1,(8=0)\end{array}$ & $\underset{(\Lambda=1, \hat{\Lambda}=0)}{\Lambda}=$ \\
\hline
\end{tabular}

Fonte: Bell, Witten e Fellows (2011, p.7)

As respostas à atividade provavelmente virão, em um primeiro momento, dispostas na base 2 , assim a solicitação de conversão para a base 10 é uma prática viável e bem-vinda neste momento. Dando continuidade, como forma de demarcação de espaço e intencionalidade lançada ao estranhamento, a atividade continua com a segunite solicitação:

Agora, tentem decifrar estes números codificados sabendo que meninas $=1$ e meninos $=0$ (figura 4 ):

Figura 4: atividade codigos relativos

a)
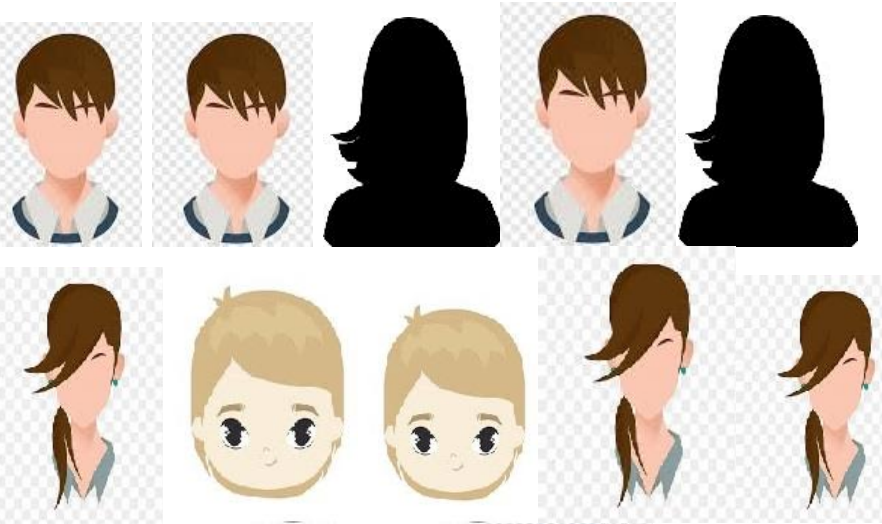

b)

c)
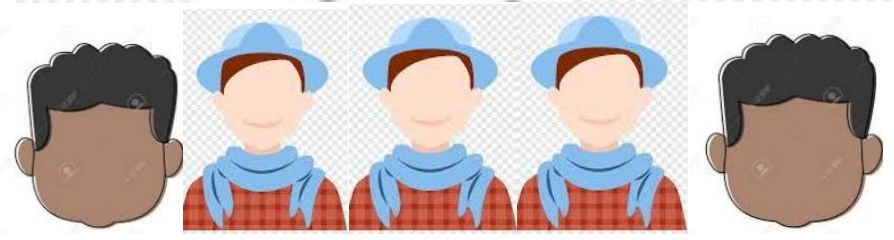

Fonte: Google Imagens. 
Com essa atividade, algumas questões precisam ser lançadas: i) quais resultados você encontrou? ii) De que forma você justifica a atribuição de valores em cada caso? iii) Como você consegue identificar quem é menino e quem é menina? iv) Você já ouviu falar em pessoas trans? De que forma? v) Após essa conversa, você trocaria os valores que possivelmente você atribuiu? Justifique. (Cabe lembrar que mesmo que as figuras das pessoas apresentadas na atividade fossem completamente esteriotipadas como "meninos" e "meninas", em cada caso, nem assim, somente pela aparência, se poderia afirmar/concluir quem seria o menino e quem seria a menina).

Nesse momento, cabe destacar que:

\begin{abstract}
A binaridade de gênero reforça a relação de dominação dos homens diante das mulheres. Os comportamentos tidos como "naturalmente femininos" ou "naturalmente masculinos" funciona de modo a alimentar essa forma de opressão e de dominação justificada como natural e não situacional, como o gênero é. Tanto o feminismo radical, quanto o feminismo interseccional, podem abrir um diálogo para repensar as fronteiras estabelecidas pelo binarismo e também repensar a relação de poder histórica que um exerce sobre o outro (ROSSINI, 2018, p.19).
\end{abstract}

Além disso, outras perspectivas precisam ser destacadas: por que a binaridade menino/menina é tão estigmatizada? Por que precisamos defini-los como se fossem números do tipo 0 e 1 ? Como seria a matemática se somente existisse 0 e 1? Você acredita, então, que só pode existir menino ou menina como se fosse 0 e 1? Sabemos que temos um sistema posicional de base 10, o que abre possibilidades, mas você acredita que só existem esses dois sistemas? Sistema posicional de base 2 e de base 10? Justifique e investigue (uso de sites de busca é aconselhável, principalmente, para debater quais seriam as palavras de busca mais adequadas - sem sugerir qualquer palavra, ou seja, sem "entregar o ouro").

A introdução a sistemas de bases diferentes cabe ser feita. Assim, além dos sitemas binário e decimal, as bases numéricas octal e hexadecimal também são utilizadas por suas representações. Dessa forma, como nas outras bases, no sistema octal (oito algarismos de 0 a 7), quando chegamos no 7, o próximo número é 10 (um e zero), ao chegar no 17, o próximo é 20 e assim sucessivamente. No sistema hexadecimal há 16 posições que são preenchidas por 10 algarismos de 0 a 9 e seis letras $(\mathrm{A}, \mathrm{B}, \mathrm{C}, \mathrm{D}, \mathrm{E}$, $\mathrm{F})$. Logo, na conversão de números de base 10 para a base hexadecimal, na divisão final, não podemos utilizar os números $10,11,12$, 13,14 , e 15 , para que não sejam confundidos com algarismos individuais ( 1 e 5 ao invés de 15, por exemplo), então, no lugar desses números utilizamos A, B, C, D, E e F. Dessa forma, por exemplo, para convertemos o número 2850 da base 10 para a base 16 (hexadecimal), dividimos 2850 por $16 \mathrm{e}$ teremos quociente 178 e resto $\mathbf{2}$, depois dividimos 178 por 16 , teremos quociente $11 \mathrm{e}$ resto 2. Como 11 não pode ser representado como está, trocamos 11 pela letra $\mathrm{B}$ ( lembre $10=\mathrm{A}, 11=\mathrm{B}, 12=\mathrm{C}, \ldots, 15=\mathrm{F})$. Chegamos, então, em B22 ou B22 16 $_{16}$ (já com índex da base hexadecimal).

Não obstante, podemos converter para a base decimal simplesmente adicionando as multiplicações de cada valor pelas potências de base 16. Isto é, $\mathrm{B} 22=\mathrm{B}(11) \cdot 16^{2}+2 \cdot 16^{1}+2 \cdot 16^{0}$ $=2816+32+2=2850$.

Para convertermos números da base binária para a base octal, a operação é semelhante à operação de conversão bináriodecimal. Se fazem necessários somente os dígitos binários de 3 em 3, da direita para a esquerda. No caso, se desejamos converter o número 11011101 2 para octal: a) Separamos os dígitos binários de $3 \mathrm{em} \mathrm{3}$, da direita para a esquerda. 11011 101. Realizamos a conversão binário-decimal para cada grupo separadamente. Ou seja, $11=1 \cdot 2^{1}+1 \cdot 2^{0}=3$, $011=0 \cdot 2^{2}+1 \cdot 2^{1}+1 \cdot 2^{0}=3,101=1 \cdot 2^{2}+0 \cdot 2^{1}+1 \cdot 2^{0}=$ 5. Logo, após unirmos novamente os dígitos, temos o número 335 na base octal ou $335_{8}$.

O inverso dessa conversão pode ser feito se cada dígito do número octal for separado e passado para a base binária separadamente. No caso, $335_{8}$ ficará 335 e, separadamente, dividimos cada algarismo por 2. Assim, 3 dividido por 2 tem quociente $\mathbf{1}$ (um) e resto $\mathbf{1}(\mathrm{um})$, fica $011_{2}$, o segundo algarismo também é 3, logo, também resulta em $011_{2}$ e o terceiro é 5, que dividido por 2 tem por quociente 2 e resto $1 . \mathrm{Na}$ sequência dividimos novamente, o quociente 2 por 2 , isto resulta em $\mathbf{1}$ com resto $\mathbf{0}$ (zero), logo o resultado é $101_{2}$. Com isso, unindo-os 
novamente temos 11011101 na base binária, ou $11011101_{2}$.

A conversão de um número da base binária para a base hexadecimal também pode ser realizada. Assim, prosseguimos separando os dígitos binários de $4 \mathrm{em} 4 \mathrm{da}$ direita para a esquerda e, antes de unir os dígitos ao final, trocamos os números 10,11 , $12,13,14$ e 15 por A, B, C, D, E e F. Seja o número $11011101_{2}$ que desejamos converter para hexadecimal. Teremos 11011101 para que possamos fazer a conversão bináriodecimal de forma independente para cada grupo. Ou seja, $1101=1 \cdot 2^{3}+1 \cdot 2^{2}+0 \cdot 2^{1}+1 \cdot 2^{0}=$ $8+4+0+1=13,1101$ repete-se, então, também é 13. Logo, teremos 1313 , os quais precisamos trocar pela letra $\mathrm{D}$, pois $13>9$. Ao trocar e unir as letras temos DD o número na base hexadecimal, ou $\mathrm{DD}_{16}$.

Para realizar a conversão reversa do exemplo anterior, ou seja, se desejamos converter um número hexadecimal para a base binária, precisamos separar os dígitos do número hexadecimal e transformar as letras em números. Assim, D D fica 13 13. Em seguida, dividimos cada número, em separado, por 2 . Logo, ao dividir 13 por 2 , obtemos quociente 6 e resto 1, seguimos e dividimos o quociente 6 novamente por 2 , obtemos quociente 3 e resto 0, dando continuidade, dividimos o quociente 3 por 2 , obtemos quociente 1 e resto $\mathbf{1}$, resultando em 1101. Como o outro número também é 13 , repetimos a operação e unimos os algarismos, resultando em 11011101 de base 2, ou $11011101_{2}$.

Essas diferentes bases e operações de transformação de base nos possibilitam ampliar a discussão. Ou seja, com a base octal, é possível atribuir valores aos rostos da atividade de números codificados e criar diferentes códigos, inclusive transformando as bases. Por exemplo:

Figura 5: atividade - base octal

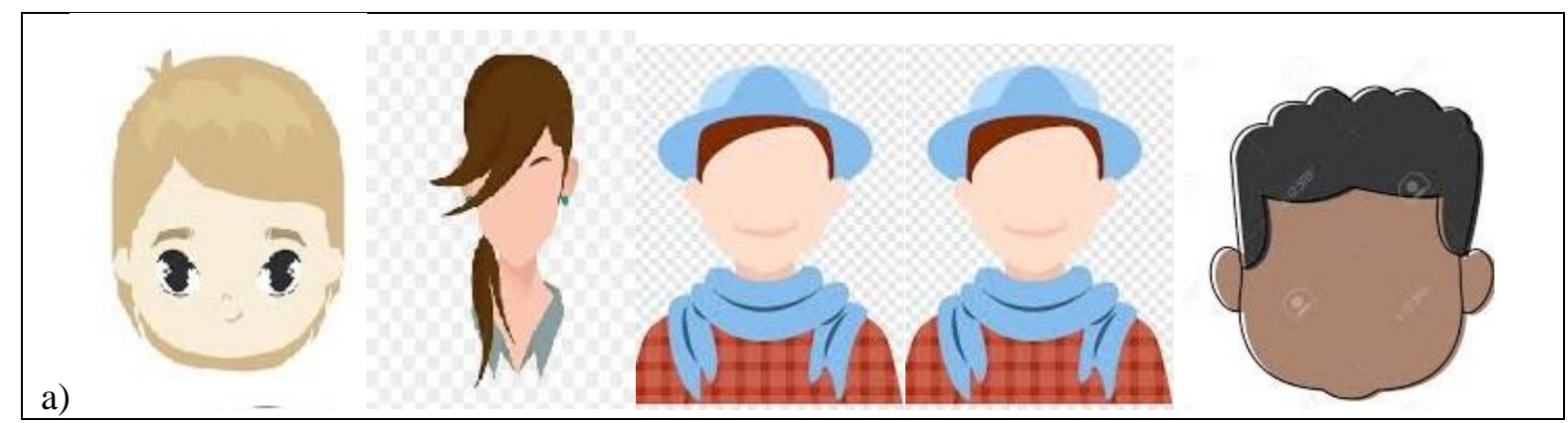

Fonte: Google Imagens

Atribua seus valores a cada imagem constituindo um número na base octal e transforme para a base decimal e para a binária. Depois modifique a ordem dos rostos, assim como crie outros. Além disso, a retomada das questões levantadas é importante. Então, só existem os sistemas posicionais de base 2 e de base 10? Quantos mais podem existir? Só existe 0 e 1 ? Só existe menino e menina na condição de gênero masculino e gênero feminino? A binaridade é a única possibilidade/condição?

Se as possibilidades são diversas, por que muitas pessoas insistem em taxar a vida dos outros/outras/outres? Como devemos agir frente a essas situações? Como nos posicionar? Como a matemática ajuda a entender possibilidades? Além do gênero, quais outras discriminações vocês conhecem? Como nos dispor a enfrentá-las enquanto sociedade?

Como afirma Butler (2020, p. 22),

$$
\begin{aligned}
& \text { A noção binária de } \\
& \text { masculino/feminino constitui não só } \\
& \text { a estrutura exclusiva em que esssa } \\
& \text { especificidade pode ser reconhecida, } \\
& \text { mas de todo modo a "especificidade" } \\
& \text { do feminino é mais uma vez } \\
& \text { totalmente descontextualizada, } \\
& \text { analítica e politicamente separada da } \\
& \text { constituição de classe, raça, etnia e } \\
& \text { outros eixos de relações de poder, os } \\
& \text { quais tanto constituem a "identidade" } \\
& \text { como tornam equívoca a noção } \\
& \text { singular de identidade. }
\end{aligned}
$$

Assim, cabe-nos prosseguir e discutir outras ideias matemáticas possíveis de 
interlocução, de intersecção a essa temática tão rica e valiosa. Dessa forma, precisamos criar, ousar, estranhar. Com isso, passamos às nossas considerações finais.

\section{Rumo à héxis política na educação matemática}

Nos propusemos a debater como a educação matemática pode ajudar a sustentar a luta da população LGBTQIA+ em termos de resistência e sobrevivência enquanto forma de se educar pela matemática para a compreensão/constituição da héxis política, frente ao respeito, à manifestação e à emersão das subjetividades de gênero. Desse modo, acreditamos que a educação matemática, enquanto paradigma educacional relativo à matemática, pode ajudar no momento em que se posicionar, ou mesmo tentar, criar uma disposição à (héxis) liberdade de todos/todas/todes (política). Isto é, ela ajuda a sustentar a luta da população LGBTQIA+ ao tratar em sala de aula as questões tão caras a essa população. Educar pela matemática, ou seja, correlacionar a própria matemática à compreensão de gênero, por exemplo, discutindo binaridade, a nosso ver, é uma forma de estranhar, de se fazer queer, consequentemente, resistir. Ou seja, levar este tipo de discussão para a sala de aula de matemática é demonstrar uma héxis política e possibilitar por parte dos/das/estudantes a compreensão ou mesmo a constituição de suas próprias héxis.

Estar disposto a pensar no outro, ser solidário, ser democrático, com reconhecimento, com respeito, é a base da educação. Logo, parafraseando o debate posto por Souza, Rodrigues e Figueiredo (2017), se um/uma/ume jovem sair, no sentido de concluir seus estudos, da escola obrigatória, persuadido de que as moças, negros, muçulmanos, gays, lésbicas, trans, outros queers, ou qualquer pessoa parte de minorias, fazem parte de categorias inferiores, pouco importa que saiba gramática, álgebra, geometria ou uma língua estrangeira, a escola terá falhado drasticamente.

Assim, este estudo discute uma de várias possibilidades presentificadas pela

\footnotetext{
14 "Guilherme Terreri Lima Pereira mais conhecido pelo nome artístico Rita von Hunty é um professor, ator, YouTuber, comediante e drag queen brasileiro, mais conhecido por participar da primeira
}

matemática para ajudar na compreensão/constituição da héxis política, frente à manifestação e à emersão das subjetividades de gênero. Assim, compreender e respeitar essas subjetividades é entender que cada posição na sigla LGBTQIA+ não é luta identitária, mas política. Cada criação, cada letra, tem um movimento político que depende de um recorte social, histórico e geográfico, o qual coloca em suspeição a forma padronizada de se pensar, assim como, as posições assumidas frente a esse modo de pensar (padronizado, dominante e heterocisnormativo).

Mesmo que um número razoável de estudantes não se identifique queer, ser aliado/aliada à causa é um movimento de respeito ao próximo e a si mesmo/mesma. A héxis política se apresenta quando cada um/uma/ume se posiciona contra, por exemplo, a projetos de lei que vetem corpos no esporte, que vetem LGBTQIA+ de aparecerem em comerciais publicitários, que queiram excluir qualquer educação sobre identidade de gênero do âmbito escolar, que coadunem com qualquer tipo de violência de gênero, que defendam qualquer tipo de LGBTQIA+fobia. Assim, não podemos e não devemos ser neutros, a matemática não é neutra (FRANKESTEIN, 1983). Como afirma Rita Von Hunty ${ }^{14}$ em LGBTQIA+(2021) "Neutro só shampoo de bebê".

Importante é destacar que assim como os números a sigla não acaba e isso não é ruim, isso é mostrar o quanto as Ciências Humanas e Sociais Aplicadas vem se debruçando e estudando o ser humano, elas se atualizam e se desenvolvem no campo de pesquisa, teorizando sexo, gênero e sexualidade. "Achar que deveria ter menos letrinhas, não entendeu nada" (RITA VON HUNTY, 2021), a questão não é mais ou menos letras na sigla, não é uma questão de criar por criar, mas de compreender o conceito de humanidade e seu alcance a outros corpos que não eram vistos como humanos. Precisamos, então, ampliar o debate de como as sociedades se estruturaram, estruturam e estruturarão e, desse modo, considerar a matemática como suporte de pesquisa, formação e educação para o bem comum.

temporada de Academia de Drags" (WIKIPÉDIA, 2021, grifo do autor). Rita, atualmente, tem um canal chamado Tempero Drag, no qual faz discussões filosóficas e políticas de largo espectro com grande profundidade e didática. 


\section{Referências}

ARENDT, H. A vida do espírito: o pensar, o querer, o julgar. Tradução de Roberto Raposo, 13 ed., Rio de Janeiro: Foresense Universitária, 2020.

ARENDT, H. Responsability and Judgment. New York: Schocken books, 2003. Disponível em: < https://docero.com.br/doc/nsn8sse>. Acesso em: 12 jun. 2021

ARENDT, H. O que é política? Tradução de Reinaldo Guarany. - 3a ed. - Rio de Janeiro: Bertrand Brasil, 2002. Disponível: <http://arquivos.eadadm.ufsc.br/somenteleitura/EaDADM/UAB_2017_1 /Modulo_1/Ciencia\%20Politica/Material\%20Com plementar/O\%20que\%20\%C3\%A9\%20pol\%C3\% ADtica\%20Hannah\%20Arendt.pdf>. Acesso em: 20 jun. 2021.

BARNETT, J. H. Origins of Boolean Algebra in the Logic of Classes: George Boole, John Venn and C. S. Peirce. Projeto (Department of Computer Science) - New Mexico State University, Las Cruces, 2011. Disponível em: $<$ https://www.cs.nmsu.edu/historicalprojects/Projects/25520111208boole-vennpeirce_05_22_11.pdf>. Acesso em: 20 jul. 2021.

BELL, T.; WITTEN, I. H.; FELOWS, M. Computer Science Unplugged: ensinando computação sem o uso do computador. Tradução de Luciano Porto Barreto. Nova Zelândia: Computer Science Unplugged, 2011.

BENDER, A.; BELLER, S. Mangarevan invention of binary steps for easier calculation. PNAS, Proceedings of the National Academy of Sciences of United States of America. Washington: National Academy of Sciences, v. 111, p. 13221327, $2014 . \quad$ Disponível em:<https://www.pnas.org/content/111/4/1322>. Acesso em: 24 ago. 2021.

BRITZMAN, D. Is there a queer pedagogy? Or, stop reading straight. Educational Theory. v. 45, n. 2. Chicago, Wiley Periodicals LLC, University of Illinois, p.151-165, 1995. Disponível em: <https://onlinelibrary.wiley.com/doi/10.1111/j.174 1-5446.1995.00151.x>. Acesso em: 20 jun. 2021.

BLOG DO ENEM. Combinação simples e com repetição de elementos: Análise Combinatória no Enem. Veja! Disponível em: $<$ https://blogdoenem.com.br/ combinacao-simplese-com-repeticao/>. Acesso em: 14 jun. 2021.

BOURDIEU, P. A Dominação Masculina: a condição feminina e a violência simbólica.
Tradução de Maria Helena Kühner. Rio de Janeiro: Bertrand Brasil, 2020.

BOURDIEU, P. O Poder Simbólico. Trad. Fernando Tomaz (português de Portugal). Tradução de: Le pouvoir symbolique. - 16. ed. Rio de Janeiro: Bertrand Brasil, 2011. 318p.

BOURDIEU, P. O Senso Prático. Trad. Maria Ferreira; rev. Odaci Luiz Coradini. Rio de Janeiro: Vozes, 2009. Tradução de: Le Sens Pratique.

BUTLER, J. Problemas de Gênero: feminismo e subversão da identidade. Tradução de Renato Aguiar, 19a edição. Rio de Janeiro: Civilização Brasileira, 2020.

\section{CASSIANO, O. Guia para "Linguagem Neutra"} (PT-BR). 2019. Disponível em: $<$ https://medium.com/guia-para-linguagem-neutrapt-br/guia-para-linguagem-neutra-pt-brf6d88311f92b>. Acesso em: 20 jun. 2021.

DALLA VECCHIA, R. A modelagem matemática e a realidade do mundo cibernético. 2012. 275 f. Tese (Doutorado em Educação Matemática) Instituto de Geociências e Ciências Exatas, Universidade Estadual Paulista "Júlio de Mesquita Filho", Rio Claro, 2012.

DICCIONARIO DE LA LINGUA ESPAÑOLA. DLS, Real Academia Española. 2021. Disponível em:

<https://dle.rae.es/extra\%C3\%B1ar\#HOuhHvr>. Acesso em: 27 ago. 2021.

DICIO. Dicionário Online de Português. 7Graus. $2009 . \quad$ Disponível em: <https://www.dicio.com.br/estranhar/>. Acesso em: 02 jul. 2020.

DUBBS, C. A Queer Turn in Mathematics Education Research: centering the experience of marginalized queer students. In. WOOD, M. B., TURNER, E. E., CIVIL, M., ELI, J. A. (Eds.). (2016). ANNUAL MEETING OF THE NORTH AMERICAN CHAPTER OF THE INTERNATIONAL GROUP FOR THE PSYCHOLOGY OF MATHEMATICS EDUCATION, 38., 2016, Tucson, Proceedings... Tucson, AZ: The University of Arizona, p.1041 1048, 2016. Disponível em: <http://www.pmena.org /pmenaproceedings/PMENA\% 2038\%202016\%20Proceedings.pdf>. Acesso em: 20 jun. 2021.

FRANKENSTEIN, M. Critical Mathematics Education: An Application of Paulo Freire's Epistemology. Journal of Education, v. 165, n. 4, p.315-339, 
1983. https://doi.org/10.1177/00220574831650040 3

HILTON, E. A revolução é transvestigênere. In.: IGNACIO, T.; DUARTE, A.; FERREIRA, G. G.; BURIGO, J.; GARCIA, T. O.; BUENO, W. Tem Saída? Perspectivas LGBTI+ sobre o Brasil. Porto Alegre: Zouk, 2020, p.11-14.

HOBUSS, J. Sobre a Disposição em Aristóteles: hexis e diathesis. DISSERTATIO Revista de Filosofia. Pelotas: Universidade Federal de Pelotas - UFPel, Instituto de Filosofia, Sociologia e Política. v.31, p.221-233, 2010. Disponível em: <https://periodicos.ufpel.edu.br/ojs2/index.php/dis sertatio/article/view/8789>. Acesso em: 08. jul. 2020 .

IFRAH, G. The Universal History of Computing: from the Abacus to the Quantum Computer. New York: John Wiley, 2001.

LAQUEUR, T. Inventando o Sexo: corpo e gênero dos gregos a Freud. Tradução. Vera Whately. Ed. Relume-Dumara. Rio de Janeiro, 2001.

LEIBNITZ, G. Explication de l'arithmétique binaire, qui se sert des seuls caractères $\mathrm{O}$ et $\mathrm{I}$ avec des remarques sur son utilité et sur ce qu'elle donne le sens des anciennes figures chinoises de Fohy. Mémoires de mathématique et de physique de l'Académie royale des sciences, Académie royale des sciences, 1703. Disponível em: $<$ https://hal.archives-ouvertes.fr/ads-

00104781/document>. Acesso em: 24 ago. 2021. ffads-00104781f.

LOURO, G. L. Um corpo estranho: ensaios sobre sexualidade e teoria queer. $3^{\mathrm{a}}$ ed ver amo.; $3^{\mathrm{a}}$ reimp. Belo Horizonte: Autêntica, 2021.

MBEMBE, A. Necropolítica: Biopoder, soberania, estado de exceção, política da morte. Arte \& Ensaios. Rio de Janeiro: PPGAV/UFRJ, n. 32, p.123-151, 2016. Disponível em: <https://www.procomum.org/wpcontent/uploads/2019/04/necropolitica.pdf >. Acesso em: 20. jun. 2021.

MENDES, H. L. Os Números Binários: do Saber Escolar ao Saber Científico. JIEEM. São Paulo: Unian, v. 10, n. 1, p. 41-49, 2017. Disponível em: < https://jieem.pgsskroton.com.br/article/view/4276> . Acesso em: 20 jul. 2021.

MIRANDA, D. Precisamos de uma revolução política para derrubar Bolsonaro. In.: IGNACIO, T.; DUARTE, A.; FERREIRA, G. G.; BURIGO, J.; GARCIA, T. O.; BUENO, W. Tem Saída? Perspectivas LGBTI+ sobre o Brasil. Porto Alegre: Zouk, 2020, p.127-138.
ROSA, M. A Construção de Identidades Online por meio do Role Playing Game: relações com o ensino e aprendizagem de matemática em um curso á distância. Tese (Doutorado em Educação Matemática) - UNESP, Rio Claro, 2008. Disponível em:

<http://www.rc.unesp.br/gpimem/downloads/teses/ rosa $\% 20 \mathrm{~m} \% 20$ doutadodo.pdf $>$. Acesso em: 20 jun. 2021.

Tessituras teórico-metodológicas em uma perspectiva investigativa na Educação Matemática: da construção da concepção de Cyberformação com professores de matemática a futuros horizontes. In: OLIVEIRA, A. M. P. de; ORTIGÃO, M. I. R. (Org.). Abordagens teóricas e metodológicas nas pesquisas em educação matemática. 1ed. Brasília: SBEM, 2018, p. 255281. Disponível em: < http://www.sbembrasil.org.br/files/ebook_.pdf $>$. Acesso em: 08 jun. 2021.

A Responsabilidade Social na Cyberformação com Professories de Matemática: uma questão de raça? In.: ROSA, M.; NETO, V. SEMINÁRIO INTERNACIONAL DE PESQUISA EM EDUCAÇÃO MATEMÁTICA, 8., 2021, Uberlândia. Anais... Brasília: SBEM, 2021. (no prelo)

Cyberformação com professories de matemática: a compreensão da héxis política à pedagogia queer. In. ESQUINCALHA, A. C. Estudos de Gênero e Sexualidades em Educação Matemática. Brasília: SBEM, 2022. Ebook (submetido)

ROSSINI, T. Binaridade, Historicidade e Feminismo. Trabalho de Conclusão de Curso (Bacharel em Psicologia). Universidade Federal Fluminense, Volta Redonda, 2018. Disponível em: $<$

https://app.uff.br/riuff/bitstream/1/9905/2/Taiza\%2 0Rossini\%20-\%20TCC.pdf>. Acesso em 05 ago. 2021.

SILVA, G. Qual o Significado da Sigla LGBTQIA+? Entenda o significado de cada letra e a sua importância para o movimento. EducamaisBrasil, 2020. Disponível em: < https://www.educamaisbrasil.com.br/educacao/dic as/qual-o-significado-da-sigla-lgbtqia>. Acesso em: 03 mar. 2021.

SOUZA, A. S.; RODRIGUES, I. M.; FIGUEIREDO, T. R. L. S. Educação, Teoria Queer e as Discussões sobre as Minorias no Espaço Escolar. Form@ re. Revista do Plano Nacional de Formação de Professores da Educação Básica. Universidade Federal do Piauí, Teresina, v. 5, n. 2, p.27-34, 2017. Disponível em: 
<https://revistas.ufpi.br/index.php/parfor/article/vi ew/6275/4064>. Acesso em: 02 fev. 2021.

LGBTQIA+: Parte II [S. 1.: s. n.], 2021. 1 vídeo (16 min). Publicado pelo Canal Tempero Drag. Disponível em <https://www.youtube.com/watch?v=j13BQD1Km IU>. Acesso em: 11 jul. 2021.

VAN NOOTEN, B. Binary Numbers in Indian Antiquity. Journal of Indian Philosophy, v. 21, n.1, p. 31-50, 1993. Disponível em:<http://www.jstor.org/stable/23445644>. Acesso em: 24 ago. 2021.
WAGNER, T. R. Hexis e Ethos: uma discussão preliminar sobre a natureza da disposição. In: ENCONTRO NACIONAL DA ANPOF, 18., 2018, Vitória, Agenda do encontro. Vitória: UFES, $2018 . \quad$ Disponível em: $<$ http://anpof.org/portal/index.php/ptBR/agenda-encontro- $\quad 2018 /$ item/559categoriaagenda2018/18782-hexis-e-ethos-umadiscussao-preliminar-sobre-a- natureza-dadisposicao >. Acesso em: 08, jul.2020.

WIKIPÉDIA. Rita Von Hunty. Disponível em: <https://pt.wikipedia.org/wiki/Rita_Von_Hunty>. Acesso em: 20 jun. 2021.

Maurício Rosa: Professor Adjunto da Universidade Federal do Rio Grande do Sul (UFRGS) - Faculdade de Educação Departamento de Ensino e Currículo e do Programa de Pós-Graduação em Ensino de Matemática (PPGEMAT). https://orcid.org/0000-0001-9682-4343. Email: mauriciomatematica@gmail.com 